\title{
ANALISIS TINGKAT PEMANFAATAN FASILITAS POKOK DI PANGKALAN PENDARATAN IKAN LONRAE KABUPATEN BONE, SULAWESI SELATAN
}

\section{ANAL YSIS OF UTILIZATION LEVEL OF MAIN FACILITIES IN LONRAE FISH LANDING, BONE DISTRICT, SOUTH SULAWESI}

\author{
Andi Eka Putri Merdekawati ${ }^{1 *}$, Achmar Mallawa $^{1}$, Faisal Amir $^{1}$ \\ ${ }^{1}$ Program Studi Pemanfaatan Sumberdaya Perikanan, FIKP, Unversitas Hasanuddin. \\ *a.ekaapm@gmail.com
}

Diterima (receive): 14 Agustus 2019; Disetujui (accepted): 03 September 2019

\begin{abstract}
ABSTRAK
Penelitian ini bertujuan untuk mengetahui tingkat pemanfaatan fasilitas pokok PPI Lonrae. Penelitian dilaksanakan pada bulan Maret sampai Mei 2019 di Pangkalan Pendaratan Ikan Lonrae, Kabupaten Bone. Metode yang digunakan dalam penelitian ini adalah Studi Kasus. Data primer meliputi panjang dermaga, jarak antar kapal, lama waktu bertambat kapal dan lama waktu trip, dan ukuran dan jumlah kapal yang berlabuh dikumpulkan melalui pengamatan langsung di lapangan. Data sekunder meliputi produksi hasil tangkapan, perkembangan jumlah dan jenis unit penangkapan, ukuran luas kolam pelabuhan, kedalaman perairan yang dikumpulkan melalui wawancara. Hasil penelitian menunjukkan bahwa fasilitas pokok yang ada di PPI Lonrae adalah dermaga, kolam pelabuhan, alur keluar masuk pelabuhan, dan daratan pelabuhan. Tingkat pemanfaatan fasilitas-fasilitas pokok di PPI Lonrae yaitu dermaga sebesar 108\%, kolam pelabuhan sebesar $45,5 \%$, daratan pelabuhan $26 \%$, dan dibutuhkan kedalaman perairan tiga meter. Hal ini berarti bahwa panjang dermaga saat ini tidak dapat menampung kapal yang berlabuh sehingga diperlukan penambahan, kolam pelabuhan, daratan pelabuhan, dan kedalaman alur pelayaran keluar masuk kapal juga perlu diperdalam.
\end{abstract}

Kata Kunci: Pangkalan Pendaratan Ikan, tingkat pemanfaatan fasilitas pokok, dermaga, kolam pelabuhan, kedalaman perairan, daratan pelabuhan

\section{ABSTRACT}

This study aimed to determine the level of utilization of the main facilities of Lonrae Fish Landing (LFL). The study was conducted from March to May 2019 at the Lonrae Fish Landing, Bone Regency. The method used in this research was the case study. Primary data included the length of the pier, the distance between ships, the length of loading and unloading of ships, the length of time of the trip, and the size and number of ships that have been docked are collected through direct observation in the field. Whereas the secondary data included the number of current catches, the number and type of capture units at present, the size of the port pond area, the depth of the waters in and out of the ship collected through interviews. The results showed that the main facilities in the LFL were the pier, harbor ponds, port entrances, and port land. The utilization level of the main facilities as follows: the pier, the port pool, and the port land were $108 \%, 45.5 \%$, and $26 \%$ respectively. The water depth required is three meters. The results suggest that the length of the jetty currently cannot accommodate ships that are anchored and therefore additional ports, port lands, and depth of shipping lanes in and out of fishing vessels need to be deepened.

Key words: Fish Landing, utilization level, fish landing main facilities, Bone district 


\section{PENDAHULUAN}

Kabupaten Bone merupakan salah satu kabupaten yang memiliki potensi perikanan tangkap yang menjanjikan. Salah satu lokasi dipesisir pantai Kabupaten Bone dengan aktivitas nelayan penangkap ikan yakni Desa Kelurahan Lonrae, Kecamatan Tanete Riattang Timur yang memiliki pelabuhan perikanan.

Pelabuhan perikanan merupakan titik temu atau titik sambung antara wilayah perairan yang merupakan daerah produksi penangkapan ikan dengan daratan sebagai wilayah distribusi dan konsumsi (Lubis, 2012). Pelabuhan terdiri atas 2 jenis yaitu pelabuhan umum dan pelabuhan khusus. Pelabuhan perikanan merupakan salah satu jenis pelabuhan khusus yang diperuntukkan bagi kegiatan penangkapan ikan, mulai dari proses produksi sampai dengan pemasaran.

Pelabuhan Perikanan (PP) dan Pangkalan Pendaratan Ikan (PPI) merupakan salah satu sarana yang penting dalam usaha perikanan tangkap. Pelabuhan memiliki peran sebagai tempat pelaksanaan sistem bisnis perikanan dan didukung dengan kegiatan pemerintahan, digunakan sebagai tempat kapal bersandar, berlabuh dan atau bongkar muat ikan serta dilengkapi dengan berbagai fasilitas dan kegiatan penunjang perikanan (DKP, 2012). Sebagai salah satu unsur penggerak ekonomi perikanan, PPI dibangun dengan tujuan untuk menunjangkeberhasilan pembangunan ekonomi perikanan terutama perikanan skala kecil.

Menurut Lubis (2012), secara umum permasalahan yang dihadapi oleh pelabuhanpelabuhan perikanan di Indonesia sangat kompleks, mulai dari terbatasnya fasilitas yang ada, lemahnya pengelolaan, hingga kurang kompetennya sumberdaya manusia pengelola pelabuhan. Hal ini ternyata berimbas pada pendapatan pengguna jasa pelabuhan perikanan, terutama nelayan selaku pelaku utama usaha perikanan tangkap. Keterbatasan kapasitas fasilitas akan berpengaruh terhadap kelancaran aktivitas kepelabuhanan sehingga fungsinya tidak tercapai secara optimal. Hal tersebut pada akhirnya akan berpengaruh terhadap perkembangan perikanan tangkapnya.

Pangkalan Pendaratan Ikan (PPI) Lonrae merupakan satu-satunya pelabuhan Tipe $D$ yang beroperasi di Kabupaten Bone. Mengingat peranan PPI yang sangat strategis, terutama dalam pengembangan usaha perikanan skala kecil atau tradisional, maka pengelolaannya harus dilaksanakan secara professional agar masyarakat nelayan dapat merasakan manfaat penuh dari keberadaan PPI.

Melihat kondisi tersebut, maka dirasa perlu untuk diadakan penelitian mengenai "Analisis 
Tingkat Pemanfaatan Fasilitas Pokok Di Pangkalan Pendaratan Ikan Lonrae Kecamatan Tanete Riattang Timur Kabupaten Bone, Sulawesi Selatan" agar fasilitas-fasilitas khusunya fasilitas pokok di PPI Lonrae dapat difungsikan secara optimal untuk menunjang perkembangan sektor perikanan di Kabupaten Bone.

Penelitian ini bertujuan untuk Mengetahui fasilitas pokok yang ada di PPI
Lonrae dan menentukan tingkat pemanfaatan fasilitas pokok di PPI Lonrae

\section{DATA DAN METODE \\ Waktu dan Tempat}

Penelitian dilaksanakan pada bulan Maret sampai Mei 2019 di Pangkalan Pendaratan Ikan Lonrae, Kecamatan Tanete Riattang Timur Kabupaten Bone. Dapat dilihat pada Gambar 1.
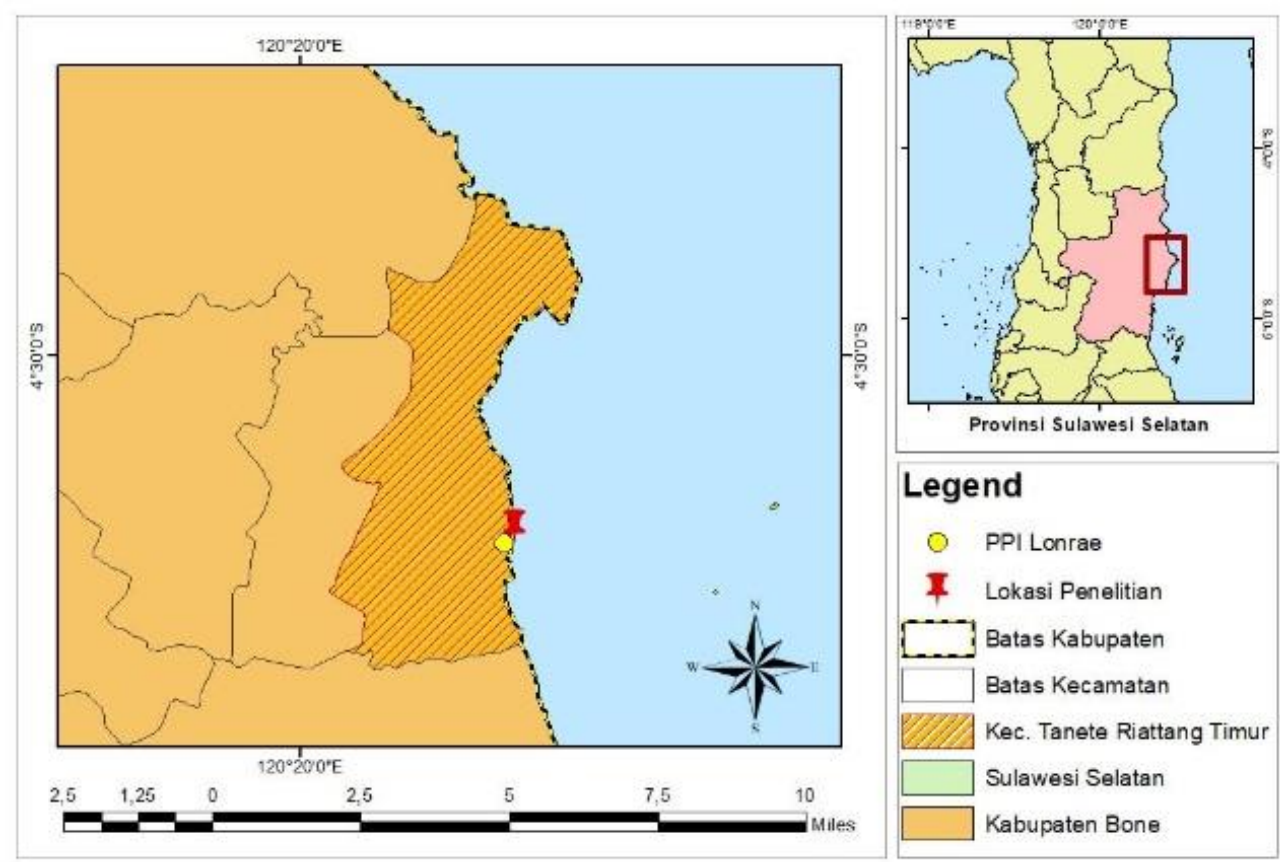

Gambar 1. Peta lokasi penelitian tingkat pemanfaatan fasilitas pokok PPI di Kabupaten Bone.

\section{Metode Penelitian}

Metode yang digunakan dalam penelitian ini adalah studi kasus. Pengambilan data dilakukan dengan cara turun langsung dilapangan, data sekunder dikumpulkan dari instansi terkait. Adapun data primer dikumpulkan dengan melakukan pengukuran langsung ke lokasi PPI.

\section{Pengambilan data primer}

Data primer diperoleh dengan cara terlibat langsung mengamati dan mengukur fasilitas yang ada di PPI Lonrae. Pengambilan data primer meliputi :

a. Pengukuran panjang dermaga menggunakan meteran. 
b. Pengukuran jarak antar kapal menggunakan meteran.

c. Mencatat waktu bertambat kapal dan waktu tiap trip.

d. Mencatat ukuran dan jumlah kapal yang berlabuh.

\section{Pengambilan data sekunder}

Data sekunder diperoleh dari pihak pengelola PPI Dinas Perikanan terkait. Pengambilan data sekunder meliputi:

a. Produksi hasil tangkapan di PPI Lonrae (minimal 5 tahun terakhir).

b. Perkembangan jumlah dan jenis unit penangkapan yang ada di Kabupaten Bone (minimal 5 tahun terakhir).

c. Pengukuran luas kolam pelabuhan, kedalaman perairan.

d. Ukuran dan jumlah fasilitas PPI

\section{Analisis Data}

Data yang diperoleh dianalisis dengan metode analisa numeric untuk menghitung ukuran dan kapasitas, lalu dianalisis untuk melihat kemungkinan pengembangan PPI kedepan. Fasilitas-fasilitas pangkalan pendaratan ikan yang akan dianalisis yaitu:

\section{Dermaga}

Panjang dermaga yang dibutuhkan saat ini dihitung dengan rumus (Nurdayana, 2013) sebagai berikut :

$$
\mathrm{Ld}=\frac{(\mathrm{I}+\mathrm{s}) \times \mathrm{n} \times \mathrm{axh}}{\mathrm{u} \times \mathrm{d}}
$$

Dimana:

Ld : Panjang dermaga (m)

I : Lebar kapal rata-rata (m)

S : Jarak antar kapal (m)

H : Lama kapal merapat di dermaga (jam)

$\mathrm{n}$ : Jumlah kapal yang menggunakan dermaga setiap hari (unit)

a : berat kapal merapat (Ton)

u : Jumlah ikan yang didaratkan oleh setiap kapal dalam sehari (Ton)

d : Lama fishing trip

\section{Luas kolam pelabuhan}

Luas kolam pelabuhan saat ini menggunakan rumus (Yahya, 2013).

$$
L=L_{t}+(3 \times n \times I \times b)
$$

Dimana:

$\mathrm{L} \quad=$ Luas kolam pelabuhan $\left(\mathrm{m}^{2}\right)$

$\mathrm{L}_{\mathrm{t}} \quad=$ Luas untuk memutar kapal $\left(\mathrm{m}^{2}\right)$

$\mathrm{n} \quad=$ Jumlah kapal maksimum yang berlabuh

I = Panjang kapal $(\mathrm{m})$

$\mathrm{b} \quad=$ Lebar kapal $(\mathrm{m})$

$\mathrm{L}_{\mathrm{t}}$ adalah luas untuk memutar kapal, radius pemutarannya minimum satu kali panjang kapal terbesar. Luas ini dihitung dengan luas lingkaran. 


$$
\mathrm{L}_{\mathrm{t}}=\pi r^{2}
$$

Dimana:

$\mathrm{L}_{\mathrm{t}}=$ Luas untuk memutar kapal $\left(\mathrm{m}^{2}\right)$

$\pi=3.14$

$\mathrm{R}=$ Panjang kapal terbesar

Untuk mengetahui luas kolam pelabuhan yang dibutuhkan oleh pelabuhan dan untuk mengetahui jumlah dan ukuran kapal yang dapat ditampung. Serta dapat beraktifitas dengan aman di kolam pelabuhan.

\section{Kedalaman perairan}

Kedalaman perairan minimal (minimum depth) yang dipersyaratkan dimana kolam pada saat muka air terendah dihitung dengan rumus (Nurdiyana, 2013) sebagai berikut :

$$
D=d+1 / 2 H+S+C
$$

Dimana:

$\mathrm{D}=$ Kedalaman peraiaran $(\mathrm{m})$

$\mathrm{d}=$ Draft kapal terbesar $(\mathrm{m})$

$\mathrm{H}=$ Tinggi gelombang maksimum $(\mathrm{m})$

$\mathrm{S}=$ Tinggi ayunan kapal yang melaju $(\mathrm{m})$

$\mathrm{C}=$ Jarak aman dari lunas kapal kedasar perairan $(m)$

\section{Daratan pelabuhan}

Luas daratan pelabuhan untuk pengembangan umumnya adalah 2 (dua) kali luas seluruh fasilitas bilamana semua fasilitas (termasuk pabrik es, depot BBM, perkantoran, dII) dibangun diatasnya (Ardandi, 2013).

\section{Tingkat Pemanfaatan}

Tingkat pemanfaatan masing-masing fasilitas pokok dianalisis secara deskriptif dengan menggunakan rumus :

Tingkat pemanfaatan $=\frac{\text { Nilai kebutuhan saat ini }}{\text { Kondisi saat dibangun }} \times 100 \%$

Apabila persentasi tingkat pemanfaatan $>85 \%$ - 100\% maka tingkat pemanfaatannya sangat tinggi, $85 \% \quad-75 \%$ tingkat pemanfaatannya tinggi dan jika $<75 \%$ maka tingkat pemanfaatannya rendah.

\section{HASIL DAN PEMBAHASAN}

\section{A. Fasilitas Pokok PPI Lonrae}

Fasilitas pokok pelabuhan adalah fasilitas dasar yang diperlukan dalam kegiatan di suatu pelabuhan. Fasilitas ini berfungsi untuk menjamin keamanan dan kelancaran kapal. Baik sewaktu berlayar keluar masuk pelabuhan maupun sewaktu berlabuh di pelabuhan (Lubis, 2012). Fasilitas pokok di PPI Lonrae ialah dermaga, kolam pelabuhan, kedalaman perairan, dan daratan pelabuhan.

\section{Dermaga}

Dermaga adalah suatu bangunan kelautan yang berfungsi sebagai tempat labuh dan bertambatnya kapal, bongkar muat hasil tangkapan, serta tempat mengisi bahan perbekalan untuk keperluan penangkapan ikan di laut (Lubis E, 2012). 
Ada beberapa tipe pemilihan dermaga yang dipengaruhi oleh topografi daerah pantai, jenis kapal yang dilayani dan daya dukung tanah. Ditinjau dari posisinya, jenis dermaga yang ada di Pangkalan Pendaratan Ikan Lonrae masuk dalam golongan dermaga yang menjorok ke laut (Jetty). Konstruksi dermaga terbuat dari beton dengan panjang 148,50 m.

\section{Kolam Pelabuhan}

Kolam pelabuhan adalah daerah perairan pelabuhan untuk masuknya kapal kapal yang akan bersandar di dermaga. Kolam pelabuhan menurut fungsinya terbagi menjadi dua yaitu, berfungsi sebagai alur pelayaran yang merupakan pintu masuk kolam pelabuhan sampai ke dermaga (navigation channe/s), dan berfungsi sebagai kolam putar yaitu daerah perairan untuk berputarnya kapal (turning basin) (Lubis, 2012). Luas kolam pelabuhan pangkalan pendaratan ikan Lonrae $220.000 \mathrm{~m}^{2}$.

\section{Kedalaman Perairan}

Untuk kelancaran pelayaran kapal didalam kolam pelabuhan dasar perairan pelabuhan harus cukup dalam, sehingga kapal dengan muatan penuh masih dapat berlayar pada saat muka air terendah (Direktorat Jendral Perikanan Tangkap, 2001).

Kapal-kapal yang melakukan bongkar muat di dermaga pangkalan pendaratan ikan
Lonrae mempunyai draft $1 \mathrm{~m}$, tinggi ayunan kapal yang melaju sekitar $0,5 \mathrm{~m}$, tinggi gelombang maksimum di kolam pelabuhan 1 m dan jarak aman dari lunas kapal kedasar perairan $1 \mathrm{~m}$. Kedalaman perairan sekarang pada saat surut terendah $1,50 \mathrm{~m}$.

\section{Daratan Pelabuhan}

Bagian darat yang menampung seluruh letak fasilitas pelabuhan disebut daratan pelabuhan (Direktorat Jendral Perikanan, 1981). Menurut Dirjen (1981), luas daratan pelabuhan untuk pengembangan umumnya adalah 2 sampai 4 kali dari luas seluruh fasilitas bilamana semua fasilitas dibangun diatasnya.

\section{B. Analisis Pemanfaatan Fasilitas Pokok PPI Lonrae}

\section{Dermaga}

Berdasarkan dari analisis perhitungan kebutuhan dermaga pangkalan pendaratan ikan Lonrae saat ini perlu dilakukan penambahan panjang dermaga sebanyak 12,21 $\mathrm{m}$ dari panjang dermaga saat ini. Tingginya tingkat pemanfaatan dermaga saat ini bahkan melebihi dari $100 \%$, hal ini dapat disebabkan oleh beberapa faktor salah satunya yaitu, saat ini jumlah kapal yang mengunakan dermaga PPI Lonrae mengalami peningkatan, dan lama kapal merapat di dermaga. 
Pada umumnya pelabuhan perikanan perlu melakukan penambahan dermaga sekitar 5 tahun. Seperti dalam penelitian yang dilakukan oleh Primsa dkk (2014) di pangkalan pendaratan ikan Pagurawan bahwa, dari hasil analisis yang dilakukan diperoleh tingkat pemanfaatan fasilitas dermaga adalah $817,32 \%$ ini berarti dermaga sudah melebihi dari sangat dimanfaatkan.

Tingginya tingkat pemanfaatan dermaga terjadi pada penelitian Yahya $\mathrm{dkk}$ (2012) di PPP Tegalsari, dermaga PPP Tegalsari memiliki panjang $1.052 \mathrm{~m}$. Berdasar perhitungan dengan data yang telah diperoleh dari lapangan panjang dermaga yang telah digunakan di PPP Tegalsari adalah 953,02 m. Nilai tersebut dapat menyimpulkan bahwa tingkat pemanfaatan dermaga PPP Tegalsari adalah $90,6 \%$.

Pada penelitian Ardandi dkk (2013) di pangkalan pendaratan ikan Tanjungsari Kabupaten Pemalang, berdasarkan data PPI Tanjungsari panjang dermaga yang ada di PPI Tanjungsari adalah 350 m, sedangkan menurut perhitungan tingkat penggunaan dermaga adalah $316,3 \mathrm{~m}$. Nilai tingkat pemanfaatan dari dermaga sebesar $90 \%$.

\section{Kolam Pelabuhan}

Berdasarkan dari analisis perhitungan kebutuhan kolam pelabuhan pangkalan pendaratan ikan Lonrae saat ini belum perlu dilakukan penambahan luas kolam pelabuhan. Tiingkat pemanfaatan kolam pelabuhan saat ini kurang dari $100 \%$, hal ini dapat disebabkan oleh beberapa faktor, salah satunya yaitu jumlah kapal yang berlabuh, dan ukuranukuran kapal yang menggunakan kolam pelabuhan.

Rendahnya tingkat pemanfaatan kolam pelabuhan kurang dari 100\% terjadi pada penelitian Yahya dkk (2012) di PPP Tegalsari, memiliki luas kolam seluas $26.000 \mathrm{~m}^{2}$. Sedangkan menurut perhitungan berdasarkan data yang diperoleh di lapangan, luas kolam pelabuhan yang telah digunakan adalah 7.496 $\mathrm{m}^{2}=0,75 \mathrm{Ha}$. Jadi, tingkat pemanfaatan dari kolam pelabuhan adalah sebesar $52,8 \%$.

Tingginya tingkat pemanfaatan kolam pelabuhan bahkan melebihi dari $100 \%$ terjadi pada penelitian Sya'rani L, dkk (2008) di pangkalan pendaratan ikan Kildang Lor Kabupaten Batang bahwa, luas kolam pelabuhan dari hasil pengukuran diperoleh luas $8.700 \mathrm{~m}^{2}$, sedangkan dari hasil perhitungan yang sesuai dengan kebutuhan diperoleh luas $11.076,25 \mathrm{~m}^{2}$, sehingga ada kekurangan sebesar $2.376,25 \mathrm{~m}^{2}$.

\section{Kedalaman Perairan}

Berdasarkan dari analisis perhitungan kedalaman perairan pelabuhan pangkalan pendaratan ikan Lonrae saat ini dilihat bahwa tingkat kebutuhan pada kedalaman perairan 
lebih dalam dari kedalaman perairan saat ini, maka perlu dilakukan penambahan, penambahan kedalaman perairan dilakukan sebanyak 0,50 m dari kedalaman perairan saat ini, karena kebutuhan kedalaman perairan saat ini $3 \mathrm{~m}$. Salah satu yang dapat menyebabkan hal ini terjadi karena di PPI Lonrae tidak mempunyai breakwater.

Tingginya tingkat pemanfaatan kolam pelabuhan terjadi pada penelitian Yahya dkk. (2012) di PPP tegalsari Kedalaman kolam perairan adalah $4 \mathrm{~m}$. Sedangkangkan penggunaan kedalaman perairan pelabuhan oleh kapal-kapal perikanan yang masuk ke PPP Tegalsari adalah 3,3 m. Sehingga tingkat pemanfaatannya adalah $82,5 \%$.

\section{Daratan Pelabuhan}

Berdasarkan dari analisis perhitungan kebutuhan daratan pelabuhan pangkalan pendaratan ikan Lonrae saat ini belum perlu dilakukan penambahan luas daratan pelabuhan, karena masih ada sebanyak 22.952 $\mathrm{m}^{2}$ daratan yang belum dimanfaatkan dari kebutuhan luas daratan pelabuhan saat ini. Sehingga masih banyak lahan kosong dari pelabuhan pangkalan pendaratan ikan Lonrae yang dapat dimanfaatkan untuk pengembangan pelabuhan.

Rendahnya tingkat pemanfaatan daratan pelabuhan juga terjadi pada penelitian Sundari dkk. (2015) di Pelabuhan Perikanan
Pantai Wonokerto dibangun dengan luas area $13.142 \mathrm{~m}^{2}$. Total penggunaan lahan pelabuhan adalah sebesar $3.820 \mathrm{~m}^{2}$, sehingga tingkat optimalisasi area pelabuhan adalah $29,1 \%$.

Pada penelitian Ardandi dkk. (2013) di pangkalan pendaratan ikan tanjungsari kabupaten pemalang, luas total dari seluruh fasilitas yang ada di PPI Tanjungsari adalah $1.450 \mathrm{~m}^{2}$, sedangkan luas lahan yang dimiliki oleh PPI Tanjungsari adalah $1.650 \mathrm{~m}^{2}$. Sehingga diketahui bahwa lahan yang digunakan oleh PPI Tanjungsari adalah 87\%.

\section{KESIMPULAN}

Berdasarkan hasil peneletian yang telah dilakukan tentang analisis tingkat pemanfaatan fasilitas pokok di pangkalan pendaratan ikan Lonrae Kecamatan Tanete Riattang Timur Kabupaten Bone Sulawesi Selatan maka dapat disimpulkan bahwa:

1. Fasilitas pokok yang ada di PPI Lonrae ialah dermaga, kolam pelabuhan, kedalaman perairan, dan daratan pelabuhan

2. Tingkat pemanfaatan fasilitas-fasilitas pokok di PPI Lonrae yaitu tingkat pemanfaatan dermaga sebesar 108\%, maka perlu diperpanjang karena kebutuhan dermaga saat ini 160,71 m. Tingkat pemanfaatan kolam pelabuhan sebesar 45,5\%, maka belum perlu dilakukan pengembangan. Tingkat 
kebutuhan pada kedalaman perairan lebih dalam dari kedalaman perairan saat ini, maka perlu dilakukan penambahan, karena kebutuhan kedalaman perairan saat ini $3 \mathrm{~m}$. Tingkat pemanfaatan daratan pelabuhan sebesar $26 \%$ maka belum perlu dilakukan pengembangan.

\section{DAFTAR PUSTAKA}

Ardandi, dkk 2013. Tingkat Pemanfaatan Fasilitas Dasar dan Fungsional Untuk Peningkatan Produksi Pangkalan Pendaratan Ikan Tangjungsari Kabupaten Pemalang. Journal of Fisheries Resources Utilization Management and Technology. Volume 21, No.1:14-15.

Departemen Kelautan dan Perikanan. 2006. Keputusan Menteri Kelautan dan Perikanan Nomor: KEP.16/MEN/2006 tentang Pelabuhan Perikanan. Jakarta: DKP.

Departemen Kelautan dan Perikanan. 2009. Undang-Undang Republik Indonesia Nomor 45 Tahun 2009 tentang Perubahan atas Undang Undang Nomor 31 Tahun 2004 tentang Perikanan pada pasal 41A ayat 2. Jakarta: DKP.

Departemen Kelautan dan Perikanan. 2012. Keputusan Menteri kelautan dan Perikanan Nomor.PER.08/MEN2012 Tentang Pelabuhan Perikanan. Jakarta.Direktorat Jendral Perikanan. 1991. Fungsi dan Peranan Sarana Pelabuhan Perikanan. Pertemuan Teknis Kepala Pelabuhan Perikanan. Jakarta: 28hal.

Direktorat Jendral Perikanan. 1994. Petunjuk Teknis Pengelolaan Pelabuhan
Perikanan. Jakarta: Direktorat Bina Prasarana.

Direktorat Jendral Perikanan. 2001. Buku Manual Operasional Pelabuhan Perikanan/Pangkalan Pendaratan Ikan. Direktorat Prasarana Perikanan Tangkap. Direktorat Jendral Perikanan Tangkap Jakarta. 132 halaman.

Direktorat Jenderal Perikanan Tangkap. 2008. Statistik Perikanan Tangkap Indonesia 2007. Jakarta: Direktorat Jenderal Perikanan Tangkap.

Kusdiantoro. 2001. Studi Pemanfaatan dan Tata Letak Fasilitas PPN Kejawanan [Skripsi]. Bogor: Fakultas Perikanan dan Ilmu Kelautan, Institut Pertanian Bogor.

Lubis E. A. B. Pane, A.R. Sam 1999. Pola Pengelolaan Pelabuhan Perikanan Yang Efisien dan Efektif di Wilayah Perairan Laut Jawa dan Laut Cina Selatan. Laporan Penelitian RUT IV. DRN. Jakarta

Lubis E. 2012. Pelabuhan Perikanan. Bogor. PT. Penerbit IPB Press, Kampus IPB Kencana Bogor

Mallawa, A., Farhum, S. A., \& dkk. (2016). Bahan Ajar Mata Kuliah Manajemen Pelabuhan Perikanan Pertemuan ke 4, Fasilitas Pokok dan Fungsional Pelabuhan Perikanan. Makassar: Program Studi Pemanfaatan Sumberdaya Perikanan, Departemen Perikanan, Fakultas Ilmu Kelautan dan Perikanan, Universitas Hasanuddin.

Manurung DN. 2006. Produktivitas Unit Penangkapan Ikan dan Komoditas Unggulan Perikanan Laut yang Berbasis di Pelabuhan Perikanan Nusantara Pekalongan [Skripsi]. Bogor: Fakultas Perikanan dan Ilmu Kelautan, Institut Pertanian Bogor.

Nurdiyana E. 2013. Tingkat Pemanfaatan Fasilitas Dasar dan Fungsional dalam Startegi Peningkatan Produksi di 
Pelabuhan Perikanan Pantai Tegalsari kota Tegal Jawa Tengah. Journal of Fisheries Resources Utilization Management and Technology. Volume 2, No.2:36-37.

Primsa PD, dkk. 2014. Studi Pemanfaatan Fasilitas Pangkalan Pendaratan Ikan Pagurawan Di Desa Nenassiam Kecamatan Medang Deras Kabupaten Batubara Provinsi Sumatera Utara. Jurnal Online Mahasiswa Fakultas Perikanan dan Ilmu Kelautan Universitas Riau

Sundari R, dkk. 2015. Analisis Tingkat Pemanfaatan Fasilitas Dasar Dan Fungsional Pelabuhan Perikanan Pantai Wonokerto Kabupaten Pekalongan. Journal of Fisheries Resources Utilization Management and Technology. Volume 4, NO. 4, HIm 188197
Sya'rani L, dkk. 2008. Evaluasi Daya Dukung Pangkalan Pendaratan Ikan Klidang Lor Kabupaten Batang untuk Pengembangan Perikanan Tangkap. Diponegoro University Institutional Repository

Yahya E, dkk. 2013. Tingkat Pemanfaatan Fasilitas Dasar dan Fungsional Dalam Strategi Peningkatan Produksi Di Pelabuhan Perikanan Pantai Tegalsari Kota Tegal Jawa Tengah. Journal of Fisheries Resources Utilization Management and Technology. Volume 21, No.1:57-58 